Article

\title{
Solid Media Thermal Energy Storage System for Heating Electric Vehicles: Advanced Concept for Highest Thermal Storage Densities
}

\author{
Volker Dreißigacker \\ Institute of Engineering Thermodynamics, German Aerospace Center, Pfaffenwaldring 38-40, \\ 70569 Stuttgart, Germany; volker.dreissigacker@dlr.de; Tel.: +49-711-6862449; Fax: +49-711-6862747
}

Received: 20 October 2020; Accepted: 11 November 2020; Published: 12 November 2020

\begin{abstract}
The integration of thermal energy storage systems enables improvements in efficiency and flexibility for numerous applications in power plants and industrial processes. By transferring such technologies to the transport sector, existing potentials can be used for thermal management concepts and new ways of providing heat can be developed. For this purpose, technology developments for solid media high-temperature thermal energy storage systems are taking place for battery-electric vehicles as part of the DLR Next Generation Car (NGC) project. The idea of such concepts is to generate heat electrically, to store it efficiently and to discharge it through a bypass concept at a defined temperature level. The decisive criterion when using such solutions are high systemic storage densities which can be achieved by storing heat at a high temperature level. However, when storing high temperature heat increasing dimensions for thermal insulation are required, leading to limitations in the achievable systemic storage density. To overcome such limitations, an alternative thermal insulation concept is presented. Up to now, conventional thermal insulations are based on sheathing the storage containment with efficient thermal insulation materials, whereby the thickness results from safety restrictions with regard to the permitted maximum surface temperature. In contrast, the alternative concept enables through the integration of the external bypass into the thermal insulation systemic advantages during the charging and discharging period. During discharging, previously unused amounts of heat or heat losses within the thermal insulation can be integrated into the bypass path and the insulation thickness can be reduced during loading through active cooling. Using detailed models for both the reference and the alternative thermal insulation concept, systematic simulation studies were conducted on the relevant influencing variables and on the basis of defined specifications. The results confirm that the alternative thermal insulation concept achieves significant improvements in systemic storage densities compared to previous solutions and high potentials to overcome existing limitations.
\end{abstract}

Keywords: solid media thermal energy storage system; high systemic thermal storage densities; heat supply; electric vehicles

\section{Introduction}

National and international obligations to protect the climate require increases in efficiency and reductions of $\mathrm{CO}_{2}$ in a wide range of different applications. Especially in the transport sector, the increased electrification of vehicles together with the expansion of renewable energy sources opens up potential for reducing emissions. Technological and economic advances, for example in battery development, make electromobility more attractive but require further efforts to increase acceptance, especially with regard to effective range. One central approach to increasing the range is based on the reduction of electrical battery capacities for heat or cold generation through the use of efficient or 
alternative thermal management concepts. Especially in cold seasons, a range loss of up to $50 \%$ [1-4] for heating the interior can be avoided by using new heating approaches.

An innovative concept for this purpose is based on the integration of an electrically heated thermal energy storage system that is used to supply heat instead of today's PTC elements (Positive Temperature Coefficient) [5]. Such thermal storage technologies have been commercial solutions in a wide range of industries $[6,7]$ for several decades or are central elements in R\&D-based large-scale electrical storage systems [8,9]. The basic principle is to store (charging period) or release heat (discharging period) in a time-decoupled operation in order to achieve improved systemic flexibility and efficiency [10]. Depending on the application, media, temperature level or systemic requirements sensible [11,12], latent $[13,14]$ or thermochemically $[15,16]$ based thermal energy storage options are suitable.

Such technologies are transferred to the transport sector mainly focused on latent and thermochemically based thermal energy storage systems. Up to now, several investigations for thermal storage systems based on Phase Change Materials (PCM) for heat supply [17-19], for preheating of catalytic converters [20] and engines [21] in combustion vehicles and ice slurry [22] for cooling applications are conducted. New thermal management concepts based on thermochemical energy storage systems (solid/gas reaction) [23] are growing in recent years, allowing an alternative heat and cold supply for electric and fuel cell vehicles.

A basic requirement for the successful use of thermal energy storages in the transport sector is vehicle-systemic benefits compared to conventional battery powered heating systems. Although both ways are based on generation heat electrically, battery storage options allow significantly higher exergetic potentials, which need to be overcome in a vehicle systemic point of view when using thermal energy storages. Thus, one central challenge of thermal energy storages in this application is strongly linked with respect to storage densities aside from further cost or flexibility benefits and must be justified on the base of today's commercial Li-Ion batteries operating in a range from $100 \mathrm{Wh} / \mathrm{kg}$ for high-power systems to $180 \mathrm{Wh} / \mathrm{kg}$ for high-energy systems [18]. So, in order to increase the attractivity of thermal energy storages for heating the interior in battery-electric vehicles, significant improvements with regard to thermal storage density are needed with simultaneously high specific charging/discharging powers.

The first one can be achieved by using high temperature heat, by utilization of phase change or reaction enthalpies and efficient thermal insulation designs. The latter needs high specific electrical charging powers, high heat transport rates (conductive and/or convective) as well as sufficient heat transport areas. A promising solution to fulfil both requirements is given by electrical heated solid media thermal energy storage systems as described in $[24,25]$, transferring heat in a direct contact between the solid and the fluid phase. During the charging period, the required heat is generated through an electrical resistance heating system, stored inside the solid material and discharged during the drive for heating the cabin by a controlled bypass via mixing the hot air exiting the storage with cold ambient air.

Promising solutions of such systems are based on the generation and storage of high-temperature heat within the solid media, with a decrease in the storage dimensions as the heating temperature increases. However, with raising heating temperatures the demand for thermal insulation increases and limits in this way the systemic storage densities due to safety-relevant restrictions. To overcome such limitations, an alternative concept is presented in this publication, which allows-compared to conventional solutions-significant improvements in systemic storage densities and increased operational flexibility.

\section{Solid Media Thermal Energy Storage System}

The use of thermal energy storage systems in battery-electric vehicles requires solutions with high systemic storage densities, which can be achieved through adequate materials, high-temperature heat and efficient thermal insulation materials with low heat conduction and density. Compared to 
reference solutions, a new concept is presented allowing increased systemic storage densities by reducing previous limitations due to safety restrictions in the maximum permitted surface temperature.

\subsection{Reference Concept}

Concepts considered so far require high-temperature solutions in order to achieve high systemic storage densities. The heat required for this is generated-parallel of charging the battery-by an electrical heating system and stored within the storage medium. Depending on the storage type, geometric, material-specific or systemic requirements, a wide range of commercial resistance-based electrical heating systems are available, where temperatures of up to $1400{ }^{\circ} \mathrm{C}$ can be reached [26].

While driving (discharging period), the thermal energy needed to heat the vehicle cabin is provided by mixing cold ambient air $\left(T_{U}\right)$ with the hot air exiting the storage $\left(T_{F, o u t}\right)$. The cold bypass flow is controlled in such a way that a constant mixed temperature $\left(T_{m i x}\right)$ at a defined temperature level (e.g., $60^{\circ} \mathrm{C}$ ) is reached despite a temperature drop of the air exiting the storage. A schematic representation for a solid-based thermal energy storage as described in [24] is shown in Figure 1.

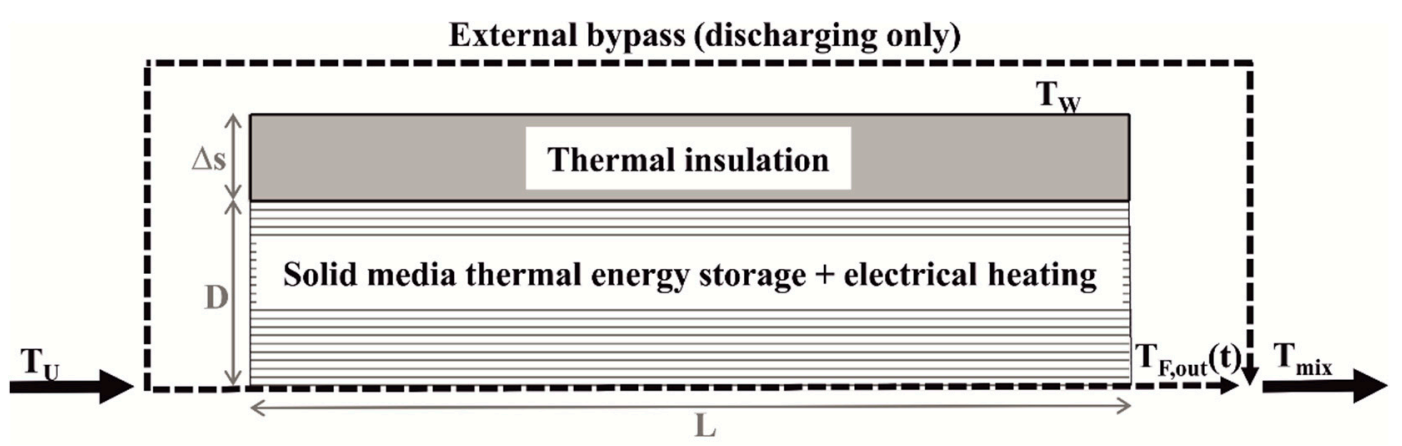

Figure 1. Reference concept—electrical heated solid media thermal energy storage with external bypass for discharging operation ( $D / L$ —storage medium diameter/length; $\Delta s$ - thermal insulation thickness).

Such thermal energy storage concepts illustrate the potential for increased range through reduced heating demands of battery-electric capacities. However, the use of such systems requires comparable or higher systemic storage densities compared to batteries [4,27] and thus high-temperature-based thermal energy storage systems. In addition to an optimized thermal design of the storage medium, the thermal insulation dimensions determine the achievable potential of systemic storage densities due to safety restrictions with regard to the maximum permitted surface temperature $\left(T_{W}\right)$.

Previous and common thermal insulation concepts are based on sheathing the thermal energy storage with a thermal insulation material, whereby the insulation thicknesses can be determined from the permitted surface temperature $\left(T_{W}\right)$ and the maximum temperature $\left(T_{P t H}\right)$ inside the storage medium. With these results, the systemic gravimetric $\left(Q / m_{t o t}\right)$ and volumetric $\left(Q / V_{t o t}\right)$ storage densities can be derived from the ratio of amount of heat $(Q)$ to be stored with the iteratively calculated dimensions of the storage medium and of the thermal insulation.

For an exemplarily microporous thermal insulation (with low density) and an $\mathrm{Al}_{2} \mathrm{O}_{3}$ based solid storage material (with high density), the central influences of both values on the resulting systemic storage densities are shown in Figure 2. The underlying contexts and assumptions are explained in detail in the following Sections 3 and 4. 


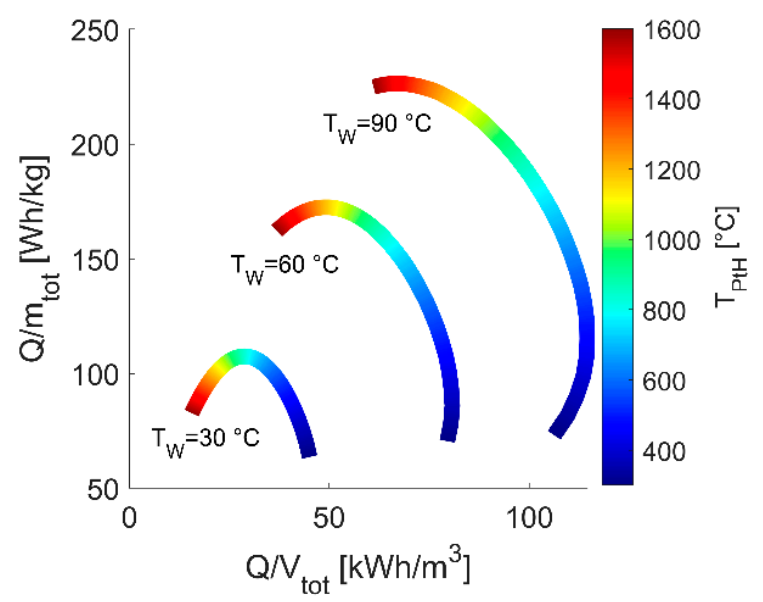

Figure 2. Systemic storage densities as a function of maximum permitted surface temperature $\left(T_{W}\right)$ and maximum solid media storage temperature $\left(T_{P t H}\right)$.

The results show a maximum in the systemic gravimetric and volumetric systemic storage densities at a constant maximum permitted surface temperature $\left(T_{W}\right)$ depending on the maximum temperatures in the thermal energy storage $\left(T_{P t H}\right)$. The reason for this behaviour is opposing effects in terms of storage medium and insulation dimensions. With increasingly maximum temperatures-thus higher temperature differences-lower storage medium masses $(m)$ and volumes $(V)$ are needed for the required heat $(Q)$ to be stored but simultaneously higher thermal insulation thicknesses are required to fulfil the specifications of maximum permitted surface temperature. As a result, local minima in the total storage masses and volumes occur depending on the material specific properties in terms of density and specific heat capacity. These opposite contexts are also evident with higher permitted surface temperatures, with a shift towards higher systemic storage densities.

These exemplary presented results point out that safety-related restrictions go hand in hand with a limitation in the systemic storage densities. Conceptual adaptions for the thermal insulation open up potential to reach significant improvements in systemic storage densities while keeping safety-related restrictions.

\subsection{Alternative Concept}

The basic idea of the alternative concept is to increase the systemic storage densities by integrating the external bypass-required for thermal discharge-into the thermal insulation. A schematic representation of this concept is shown in Figure 3.

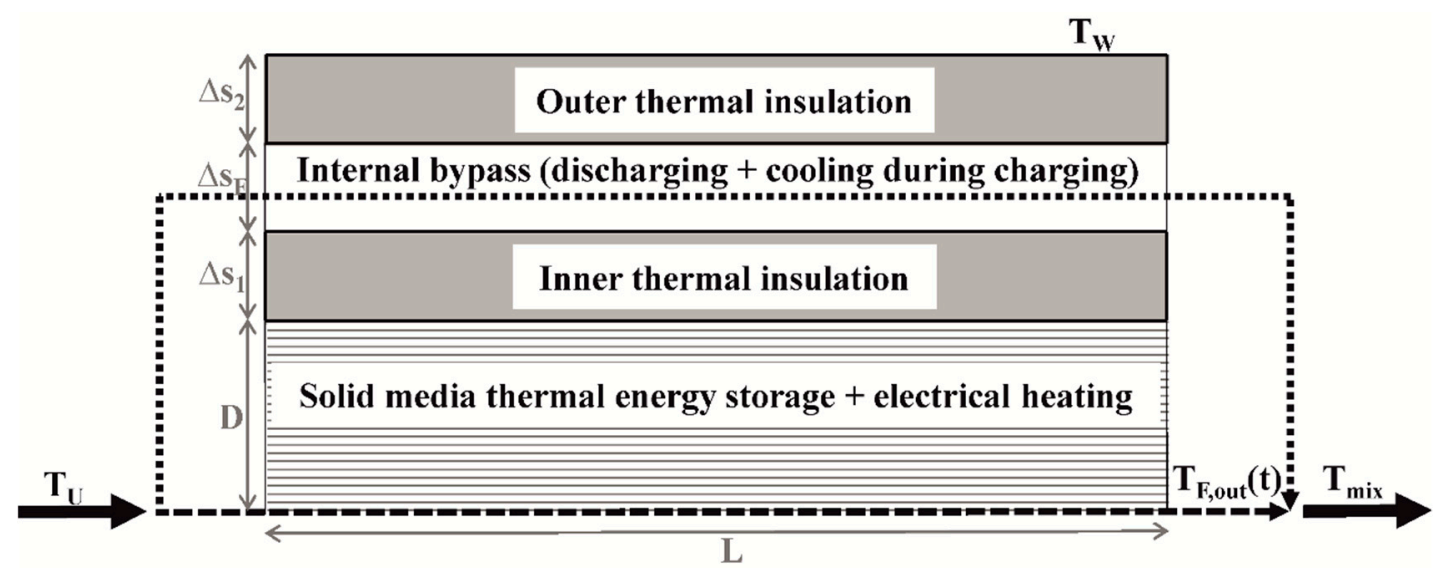

Figure 3. Alternative concept-electrical heated solid media thermal energy storage with internal bypass for discharging and charging operation ( $D / L$ —storage medium diameter/length; $\Delta s_{1} / \Delta s_{2}$-inner/outer thermal insulation thickness; $\Delta s_{F}$-fluid gap). 
During the thermal discharge period, previously unused heat losses or stored heat in the thermal insulation can be integrated into the bypass path, which allows longer discharge times through a preheated bypass temperature. At the same time, the integrated path enables an active cooling of the thermal insulation during charging period and thus a reduction in the required insulation thickness. Both options open up the potential to increase the systemic storage densities through higher utilization of the heat stored in the system and through active cooling.

For evaluating the reachable potentials of the alternative concept compared to the reference one in terms of systemic storage densities, heat losses and required thermal cooling powers, detailed simulation studies regarding the thermal insulation and gap thicknesses are needed.

\subsection{Methodology}

In order to investigate the alternative concept and to allow comparative statements to the reference concept, it is necessary to identify in a first step favoured design solutions for the solid storage medium on the basis of defined boundary conditions and target values during thermal discharging period. The resulting geometric specifications for an example solution (Section 4.1) with regard to storage medium diameter and length form in a next step the basis to investigate the thermal insulation for both the reference and the alternative concept (Section 4.2). Open questions regarding the integration location of the air-cooled duct as well as the associated heat flows are systematically investigated and serve finally as basis for identifying a first design solution of the alternative concept with high systemic storage density compared to the reference concept (Section 4.3).

Due to the safety-related restrictions with regard to the maximum permitted surface temperature, the end of the charging period is seen as the critical subprocess, whereby the solid medium was homogenously heated by the electrical heating system at a maximum temperature. For these steady-state conditions, the resulting temperature profiles and heat flows to the environment serve as central quantities to determine the systemic storage densities and for evaluating both thermal insulation concepts.

\section{Modelling}

The investigations are based on successive simulation studies for the storage medium, the reference thermal insulation and the double-walled thermal insulation structure. For each system considered here, the fundamental heat balance equations and the central boundary conditions as well as simulation procedures are explained below.

\subsection{Solid Media Thermal Energy Storage Systems}

For modelling the discharge procedure of a solid media thermal energy storage system, a one-dimensional cylindrical heterogeneous porous continuum approach is used, providing the axial temperature characteristics for the gaseous $(F)$ and the solid phase $(S)$ in time $(t)$ and space $(z)$ [28]. Under ideal assumptions with neglections of thermal losses and of the axial heat conduction term due to low heat conductivities for the fluid and solid phase compared to the convective part, the thermal energy balances can be simplified to

$$
\begin{gathered}
\varepsilon \rho_{F} c_{F}\left(\frac{\partial T_{F}}{\partial t}+w \frac{\partial T_{F}}{\partial z}\right)=k a_{V}\left(T_{S}-T_{F}\right) \\
(1-\varepsilon) \rho_{S} c_{S} \frac{\partial T_{S}}{\partial t}=k a_{V}\left(T_{F}-T_{S}\right)
\end{gathered}
$$

where the fluid and solid medium temperature are represented by $T_{F}$ and $T_{S}$, the fluid velocity by $w$, the void fraction by $\varepsilon$ and the specific heat transfer surface by $a_{V}$. The total regenerator heat transfer coefficient $k$ is calculated according to Hausen $[29,30]$ including in a compact way the temporal averaged heat resistance inside the solid phase as well as the heat transfer coefficient of the fluid for the investigated channel-shaped bricks [29]. Additionally, temperature dependent material properties 
such as the density $\rho$ and specific heat capacity $c_{P}$ are needed, given by the selected solid medium as well as by a real gas model for air [31].

After defining the inlet boundary conditions for the fluid phase, the adiabatic conditions for the solid phase

$$
\begin{gathered}
\left.T_{F}\right|_{z=0}=T_{U} \\
\left.\frac{\partial T_{S}}{\partial z}\right|_{z=0 \& z=L}=0
\end{gathered}
$$

and by using a central and a backward finite-difference-method in space for the solid and for the fluid phase, the resulting set of differential algebraic equations are solved in time with a commercial simulation tool (Matlab). Mesh studies were performed in order to allow a deviation of less than $10^{-4}$ relating to the fluid outlet temperature leading to an axial discretization of at least 50 nodes.

For qualifying the thermal efficiency of different channel-shaped geometric storage medium solutions, a central value for such types of thermal energy storages is introduced in Equation (5). This quantity - the thermal utilization coefficient $\left(\eta_{\text {store }}\right)$-represents the ratio of effective to maximal possible discharged thermal energy and is used in the following for comparing different geometric solutions.

$$
\eta_{\text {store }}=\frac{c_{S} T_{P t H}-\int_{0}^{1}\left[c_{S} T_{S}(z, t=\tau)\right] \frac{d z}{L}}{c_{S} T_{P t H}-c_{S} T_{U}}
$$

Aside of the described modelling details, a simulation control procedure is integrated inside the unsteady simulation runs to divide the inlet mass flow in a bypass and a storage medium passing part. In an iteratively operating way, the bypass flow during discharging period at ambient condition and the storage medium exiting flow at elevated temperature is controlled in order to fulfil the specifications of a constant mixed outlet temperature. A maximum deviation inside the iteratively simulation runs of less than $10^{-4}$ relating to the constant mixed outlet temperature was allowed.

\subsection{Thermal Insulation}

The investigation and evaluation of the reference and the alternative concept is based on steady state conditions, whereby the solid medium is assumed to be homogenously heated by the electrical heating system at the maximum temperature $\left(T_{P t H}\right)$. Due to the integrated bypass path inside the alternative construction, a two-dimensional formulation of the thermal insulation with its material-specific thermal diffusivity $a_{I n s}$ is necessary, which enables the calculation of the axial $(z)$ and radial $(r)$ temperature profiles $\left(T_{\text {Ins, },}\right)$ as described in Equation (6) [32].

$$
\frac{\partial T_{\text {Ins }, j}}{\partial t}=0=a_{\text {Ins }}\left(\frac{\partial^{2} T_{\text {Ins, }, j}}{\partial z^{2}}+\frac{\partial^{2} T_{\text {Ins }, j}}{\partial r^{2}}+\frac{1}{r} \frac{\partial T_{\text {Ins }, j}}{\partial r}\right)
$$

A one-dimensional model (Equation (7)) is used to determine the cooling flow air temperatures $\left(T_{F, c}\right)$ at a given velocity $w_{\mathcal{c}}$.

$$
\frac{\partial T_{F, c}}{\partial t}=0=\frac{\alpha_{c}}{\rho_{F} c_{F}}\left[a_{V c, 1}\left(\left.\frac{\partial T_{I n s 1}}{\partial r}\right|_{r=\mathrm{D} / 2+\Delta s_{1}}-T_{F, c}\right)+a_{V c, 2}\left(\left.\frac{\partial T_{T h s 2}}{\partial r}\right|_{r=\mathrm{D} / 2+\Delta s_{1}+\Delta s_{F}}-T_{F, c}\right)\right]-w_{c} \frac{\partial T_{F, c}}{\partial z}
$$

Here, heat is transferred from the inner $(j=1)$ and outer $(j=2)$ thermal insulation $\left(T_{I n s, j}\right)$ to the cooling air at the gap specific surfaces $\left(a_{V c, j}\right)$ through a convective heat transport coefficient $\left(\alpha_{c}\right)$ according to [33].

These heat balance equations form the basis for the conducted simulation studies in Section 4, whereby only Equation (6) is required for the reference concept and Equations (6) and (7) for alternative concept. To solve the resulting systems of equations, boundary conditions are required as summarized in Tables 1 and 2 depending on the thermal insulation system. 
Table 1. Boundary conditions for the reference concept.

\begin{tabular}{cc}
\hline Boundary Condition & Equation \\
\hline$\left.\frac{\partial T_{I n s}}{\partial z}\right|_{z=0 \& z=L}=0$ & $(8)$ \\
\hline$\left.T_{I n s}\right|_{r=\mathrm{D} / 2}=T_{P t H}$ & (9) \\
\hline$\left.\lambda_{I n s} \frac{\partial T_{I n s}}{\partial r}\right|_{r=\mathrm{D} / 2+\Delta \mathrm{s}}=\alpha_{W}\left(T_{U}-T_{I n s}\right)$ & $(10)$ \\
\hline
\end{tabular}

Table 2. Boundary conditions for the alternative concept.

\begin{tabular}{|c|c|}
\hline Boundary Condition & Equation \\
\hline$\left.\frac{\partial T_{\text {Ins1 }}}{\partial z}\right|_{z=0 \& z=L}=0$ & (11) \\
\hline$\left.T_{I n s 1}\right|_{r=\mathrm{D} / 2}=T_{P t H}$ & $(12)$ \\
\hline$\left.\lambda_{I n s} \frac{\partial T_{I n s 1}}{\partial r}\right|_{r=\mathrm{D} / 2+\Delta s_{1}}=\alpha_{c}\left(T_{F, c}-T_{I n s 1}\right)+C_{r, 21}\left[\left(\left.T_{I n s 2}\right|_{r=\mathrm{D} / 2+\Delta s_{1}+\Delta s_{F}}\right)^{4}-T_{I n s 1}^{4}\right]$ & (13) \\
\hline$\left.\frac{\partial T_{\text {Ins2 }}}{\partial z}\right|_{z=0 \& z=L}=0$ & (14) \\
\hline$\left.\lambda_{I n s} \frac{\partial T_{\text {Ins } 2}}{\partial r}\right|_{r=\mathrm{D} / 2+\Delta s_{1}+\Delta s_{F}}=\alpha_{c}\left(T_{F, c}-T_{I n s 2}\right)+C_{r, 12}\left[\left(\left.T_{I n s 1}\right|_{r=\mathrm{D} / 2+\Delta s_{1}}\right)^{4}-T_{I n s 2}^{4}\right]$ & $(15)$ \\
\hline$\left.\lambda_{\text {Ins }} \frac{\partial T_{\text {Ins } 2}}{\partial r}\right|_{r=\mathrm{D} / 2+\Delta s_{1}+\Delta s_{F}+\Delta s_{2}}=\alpha_{W}\left(T_{U}-T_{\text {Ins } 2}\right)$ & (16) \\
\hline$\left.T_{F, c}\right|_{z=0}=T_{U}$ & (17) \\
\hline
\end{tabular}

Adiabatic conditions are defined for the axial boundaries (Equations (8), (11) and (14)) and convective heat losses by $\alpha_{W}$ [34] as well as temperature conditions by $T_{P t H}$ for the radial boundaries at the outer (Equations (10) and (16)) and at the inner insulation surface (Equations (9) and (12)) respectively. Additionally, radial boundary conditions for the alternative concept between the inner and outer thermal insulation surfaces are required (Equations (13) and (15)), which include heat transport via radiation by $\mathrm{C}_{r}$ and convection by $\alpha_{\mathrm{c}}$.

This radiation parameter $C_{r}$ is based on a geometry-dependent formulation of the parameters $\varphi_{12}$ and $\varphi_{21}$ for the inner $(j=1)$ and outer $(j=2)$ thermal insulation dimension according to [35], the emission coefficient $\left(\beta_{j}\right)$ and Stefan-Boltzmann constant $(\sigma)$ as described in Equations (18) and (19):

$$
\begin{aligned}
& C_{r, 12}=\sigma \frac{\beta_{1} \beta_{2} \varphi_{12}}{1-\left(1-\beta_{1}\right)\left(1-\beta_{2}\right) \varphi_{12} \varphi_{21}} \\
& C_{r, 21}=\sigma \frac{\beta_{1} \beta_{2} \varphi_{21}}{1-\left(1-\beta_{1}\right)\left(1-\beta_{2}\right) \varphi_{12} \varphi_{21}}
\end{aligned}
$$

Here, a value of 0.7 is being used for the emission coefficients leading to radiation parameters $C_{r}$ for the conducted simulation studies of about $1 \times 10^{-8} \mathrm{~W} / \mathrm{m}^{2} \mathrm{~K}^{4}$ to $3 \times 10^{-8} \mathrm{~W} / \mathrm{m}^{2} \mathrm{~K}^{4}$.

With the temperature-based boundary condition for the cooling flow (Equation (17)) and after spatial discretization, the set of nonlinear equations is solved by using the Newton-Raphson method in a commercial software (Matlab). Mesh studies were performed in order to allow a deviation of less than $10^{-4}$ relating to the insulation surface temperature leading to an axial discretization of at least 15 nodes.

\section{Results}

The investigations of the thermal insulations are initially based on idealized calculations for the thermal energy storage medium and on the identification of a favoured geometric solution with high thermal storage utilization (Section 4.1). The resulting storage medium dimensions form the basis for 
investigating the reference and the alternative concept (Section 4.2) and for comparing statements with regard to systemic storage density, heat losses and thermal cooling powers (Section 4.3).

Central process specifications regarding design calculations of the solid media thermal energy storage systems during discharging period are summarized in Table 3.

Table 3. Storage medium—specifications and selected material.

\begin{tabular}{cccccc}
\hline$\dot{Q}[\mathrm{~kW}]$ & $\boldsymbol{T}_{\text {mix }}\left[{ }^{\circ} \mathrm{C}\right]$ & $\boldsymbol{T}_{\boldsymbol{U}}\left[{ }^{\circ} \mathrm{C}\right]$ & $\tau[\mathrm{h}]$ & $\Delta p$ [mbar] & Storage Medium: $\mathrm{Al}_{2} \mathrm{O}_{3}[36]$ \\
\hline 5 & 60 & -10 & 0.5 & 10 & $\rho\left[\mathrm{kg} / \mathrm{m}^{3}\right]$ \\
\hline
\end{tabular}

These central process specifications with regard to the thermal discharge power $(\dot{Q})$, the constant mixing outlet temperature $\left(T_{m i x}\right)$, the ambient temperature $\left(T_{U}\right)$, the discharge duration $(\tau)$ and the maximum permitted pressure loss $(\Delta p)$ are based on requirements for cabin heat supply of battery-electric vehicles on cold winter times $[19,24]$.

As preferred storage medium material an $\mathrm{Al}_{2} \mathrm{O}_{3}$ ceramic is selected, which-compared to alternative ceramic or metallic materials-permits high storage densities and high operating temperatures. Such ceramics are available as commercial products (e.g., honeycombs, checker bricks) with a wide range of geometric shapes through different manufacturing processes.

The specifications required for designing the thermal insulations with regard to the maximum permitted surface temperature $\left(T_{W}\right)$ and the maximum cooling flow outlet temperature $\left(T_{F, c \text {-out }}\right)$ are summarized in Table 4.

Table 4. Thermal insulation-specifications and selected material.

\begin{tabular}{ccc}
\hline$T_{W}\left[{ }^{\circ} \mathrm{C}\right]$ & $\boldsymbol{T}_{\boldsymbol{F}, \mathrm{c} \text {-out }}\left[{ }^{\circ} \mathrm{C}\right]$ & Insulation: Microporous [37] \\
\hline \multirow{2}{*}{60} & 60 & $\rho\left[\mathrm{kg} / \mathrm{m}^{3}\right]$ \\
\cline { 2 - 2 } & & $160\left(0^{\circ} \mathrm{C}\right)$ \\
\hline
\end{tabular}

The defined limit temperatures of $60{ }^{\circ} \mathrm{C}$ are based on safety-related restrictions allowing the integration of such thermal storage systems in the immediate vicinity of passengers [38].

Due to the generation and storage of heat at a high temperature level, a microporous insulation material is preferred here. Such materials have low heat conductions as well as densities and are therefore suitable solutions for compact thermal insulations. Among a large number of commercially available products-some with comparable thermophysical properties—the product Silcaflex 160 [37] with maximum operating temperatures of $1600{ }^{\circ} \mathrm{C}$ was chosen exemplarily as basis for design calculations of the thermal insulations.

\subsection{Solid Media Thermal Energy Storage Systems}

For investigations the thermal insulations, geometric design solutions of the storage medium must be identified based on the specifications in Table 3 , which enable high storage utilization $\left(\eta_{\text {store }}\right)$ during the discharging period. Using the idealized one-dimensional model equations and the bypass control from Section 3.1, wide variation studies were performed with regard to specific surface $\left(a_{V}\right)$, void fraction $(\varepsilon)$, length-to-diameter ratio $(L / D)$ and initially temperature inside the storage material $\left(T_{P t H}\right)$. Central results for the storage utilization depending on those relevant geometric values at exemplary maximum storage temperatures of $1000^{\circ} \mathrm{C}$ are shown in Figure 4. 


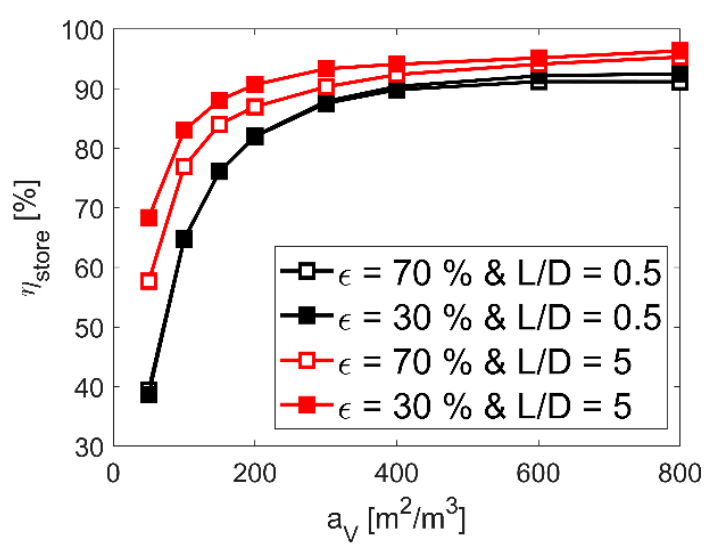

Figure 4. Storage utilization $\left(\eta_{\text {store }}\right)$ as a function of specific surface $\left(a_{V}\right)$, void fraction $(\varepsilon)$ and length-to-diameter ratio $(L / D)$ at an exemplarily selected maximum solid media storage temperature $\left(T_{P t H}\right)$ of $1000^{\circ} \mathrm{C}$.

The results show higher specific surfaces significantly increasing storage utilization. For sufficient high specific surfaces, moderate improvements in storage utilization can be achieved through higher $L / D$ ratios due to increased heat transfer coefficients. Fewer influences on the storage utilization can be seen by the void fraction. Though with smaller void fractions, the velocities and so the convective heat transport coefficients increase, but at the same time the duration times of the fluid inside the storage medium are reduced and thus so is the period for heat transport. Comparable characteristics with minor deviations result also at different maximum temperatures, whereby higher temperatures are associated with an increase in the storage medium-related storage densities.

Based on the solutions shown in Figure 4 and the interrelation explained, a storage medium with a specific surface $\left(a_{V}\right)$ of $400 \mathrm{~m}^{2} / \mathrm{m}^{3}$, a L/D ratio of 4 and a maximum temperature $\left(T_{P t H}\right)$ of $1000{ }^{\circ} \mathrm{C}$ was selected for the upcoming investigations on the thermal insulations. Although the electrothermal charging is not focused on in this study, the selected maximum temperature of the storage medium of $1000{ }^{\circ} \mathrm{C}$ corresponds to industrial heating solutions from high-temperature applications (e.g., furnace technology) that are based on open heating wire systems with heating temperatures of up to $1400{ }^{\circ} \mathrm{C}$ [26]. Central values regarding this solution are summarized in Table 5.

Table 5. Storage medium (SM)—central results for the selected solution at maximum temperature of $1000{ }^{\circ} \mathrm{C}$.

\begin{tabular}{ccccccc}
\hline$m_{S M}[\mathrm{~kg}]$ & $V_{S M}[1]$ & $D[\mathrm{~mm}]$ & $L[\mathrm{~mm}]$ & $\eta_{\text {store }}[\%]$ & $Q / m_{S M}[\mathrm{Wh} / \mathrm{kg}]$ & $Q / V_{S M}\left[\mathrm{kWh} / \mathrm{m}^{3}\right]$ \\
\hline 8.2 & 3.4 & 103 & 412 & 92.7 & 304.1 & 728.4 \\
\hline
\end{tabular}

To limit the maximum pressure loss during discharging to the specified $10 \mathrm{mbar}$, a minimum void fraction $(\varepsilon)$ of $40 \%$ is permitted. These pressure losses are calculated according to [39] for the investigated channel-shaped bricks, whereby the relevant geometric quantity-the channel diameter $d$-is derived from geometric relations with respect to the specific surface $a_{V}$ and the void fraction $\varepsilon$ as described in Equation (20):

$$
d=4 \frac{\varepsilon}{a_{V}}
$$

Here, an absolute channel roughness of $5 \times 10^{-4} \mathrm{~m}$ was assumed while calculating the pressure losses in the turbulent range, which is a typical value for ceramic manufactured pipes. 


\subsection{Thermal Insulation}

\subsubsection{Reference Concept}

Based on the microporous thermal insulation material, the storage medium solution and the maximum temperature, variation calculations were performed on the permitted maximum surface temperature $\left(T_{W}\right)$. In an iterative way, the thermal insulation thicknesses $(\Delta s)$ are determined, resulting in the thermal insulation dimensions and with respect to the storage medium solution to the systemic storage densities. Those results together with the associated heat losses are shown in Figure 5 for permitted maximum surface temperatures from $10{ }^{\circ} \mathrm{C}$ to $200^{\circ} \mathrm{C}$.

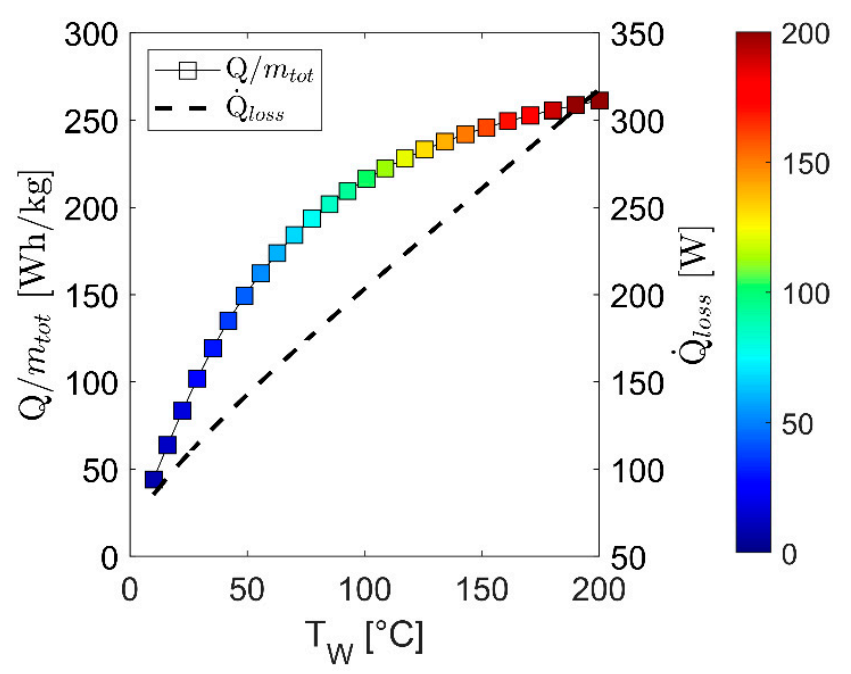

Figure 5. Systemic storage densities $\left(Q / m_{t o t}, Q / V_{t o t}\right)$ and heat losses $\left(\dot{Q}_{\text {loss }}\right)$ as a function of the permitted maximum surface temperature $\left(T_{W}\right)$.

The characteristic of the systemic storage densities illustrates decreasing systemic storage densities with higher requirements for the permitted maximum surface temperatures. At maximum surface temperatures of $60^{\circ} \mathrm{C}$, gravimetric and volumetric systemic storage densities of $169.2 \mathrm{Wh} / \mathrm{kg}$ and $56.3 \mathrm{kWh} / \mathrm{m}^{3}$ are reached, whereas moderately higher permitted surface temperatures of $120^{\circ} \mathrm{C}$ result in a significant increase in systemic storage densities to $229.7 \mathrm{Wh} / \mathrm{kg}$ and $124.5 \mathrm{kWh} / \mathrm{m}^{3}$. Simultaneously, the improvements are associated with increasing thermal losses. For the maximum permitted surface temperature of $60^{\circ} \mathrm{C}$ as specified in Table 4, heat losses of $155.3 \mathrm{~W}$ are resulting at a required insulation thickness of $134 \mathrm{~mm}$. Central results are summarized in Table 6 and serve as a base for comparing the reference with the alternative concepts.

Table 6. Reference concept—central results at maximum permitted surface temperature of $60^{\circ} \mathrm{C}$.

\begin{tabular}{cccc}
\hline$Q / m_{\text {tot }}[\mathrm{Wh} / \mathrm{kg}]$ & $Q / V_{\text {tot }}\left[\mathrm{kWh} / \mathrm{m}^{3}\right]$ & $\dot{Q}_{\text {loss }}[\mathrm{W}]$ & $\Delta s[\mathrm{~mm}]$ \\
\hline 169.2 & 56.3 & 155.3 & 134 \\
\hline
\end{tabular}

Even with conventional thermal insulation solutions, the characteristics show significant improvements in systemic storage densities, when safety-related restrictions regarding the permitted maximum surface temperatures are neglected. To use these potentials without exceeding the safety-related restrictions, the alternative concept is investigated in the following. 


\subsubsection{Alternative Concept}

The simulation studies for the alternative concept are-analogous to the reference concept-based on the microporous thermal insulation material, the storage medium solution and the maximum temperature. The inner $\left(\Delta s_{1}\right)$ and outer $\left(\Delta s_{2}\right)$ insulation thicknesses as well as the cooling fluid gap $\left(\Delta s_{F}\right)$ were determined iteratively to fulfil the defined specifications (Table 4) of maximum permitted surface temperature and cooling flow outlet temperatures of each $60^{\circ} \mathrm{C}$.

For an example solution $\left(\Delta s_{F}=25 \mathrm{~mm}\right)$, the resulting active cooling mass rates $\left(\dot{m}_{F, c}\right)$ are shown in Figure 6 as a function of the insulation thicknesses.

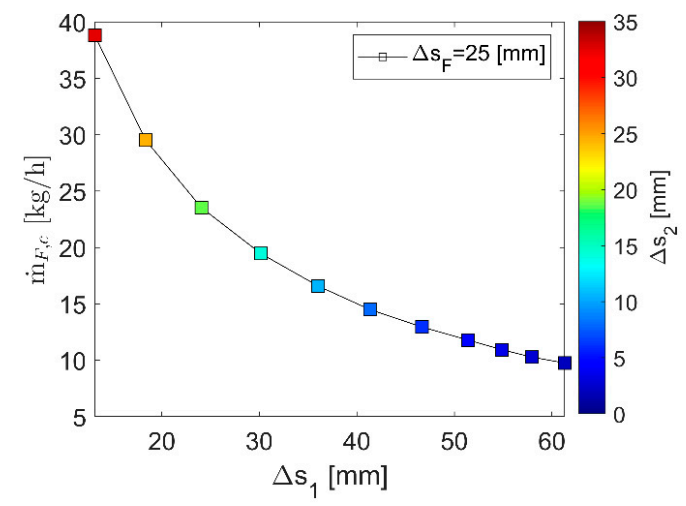

Figure 6. Cooling mass flow rates $\left(\dot{m}_{F, c}\right)$ as a function of inner $\left(\Delta s_{1}\right)$ and outer $\left(\Delta s_{2}\right)$ thermal insulation thicknesses at an exemplarily selected cooling fluid gap $\left(\Delta s_{F}\right)$.

The results show with smaller thicknesses of the inner thermal insulation $\left(\Delta s_{1}\right)$-due to higher insulation temperatures there-increasing active cooling mass flow rates in order to achieve the specified cooling flow outlet temperatures of $60^{\circ} \mathrm{C}$. At the same time-despite the increasing active cooling with decreasing inner thermal insulation thickness-higher outer thermal insulation thicknesses $\left(\Delta s_{2}\right.$ - colored dots) are required to guarantee the maximum permitted surface temperature of $60^{\circ} \mathrm{C}$. The reason for this behaviour is associated with increasing heat flow rates by thermal radiation, which leads-despite the existing convective cooling - to an increase in temperatures in the outer thermal insulation. Comparable characteristics can also be seen for other investigated gap thicknesses $\left(\Delta s_{F}\right)$, whereby smaller gap thicknesses lead to lower thermal insulation thicknesses due to higher cooling efficiencies.

This behaviour is illustrated in the following Figure 7 together with the resulting heat losses and the summed up thermal insulation masses.

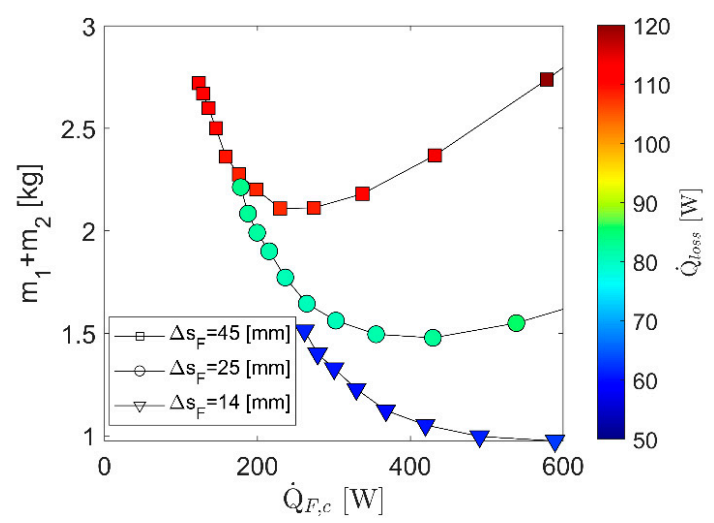

Figure 7. Total mass of the inner $\left(m_{1}\right)$ and outer $\left(m_{2}\right)$ thermal insulation as well as heat losses $\left(\dot{Q}_{l o s s}\right)$ and volumetric systemic storage densities of the reference and the alternative concept as a function of the resulting thermal cooling powers $\left(\dot{Q}_{F, c}\right)$. 
As already described above, the results show with smaller gap thicknesses $\left(\Delta s_{F}\right)$ significant lower total thermal insulation masses due to the improved cooling efficiency. This leads at the same time to smaller storage volumes and thus, due to the specified maximum surface temperature of $60^{\circ} \mathrm{C}$, to lower heat losses $\left(\dot{Q}_{\text {loss }}\right.$-coloured dots). Based on the specified restrictions of a maximum cooling outlet temperature of $60^{\circ} \mathrm{C}$, the minimum required active cooling mass rates or thermal powers $\left(\dot{Q}_{F, c}\right)$ increase with decreasing gap thicknesses. So, with gap thicknesses of $14 \mathrm{~mm}$ minimum active cooling powers of $261.7 \mathrm{~W}$ are needed, whereas with gap thicknesses of $45 \mathrm{~mm}$ minimum active cooling powers of $123.4 \mathrm{~W}$ are reached.

In addition, the characteristics show, depending on the geometric solution spaces, minima in the summed up thermal insulation masses. The reason for this is the described behaviour in Figure 6 of increasing outer with decreasing inner thermal insulation thicknesses in interaction with the active cooling flow and the thermal radiation.

\subsection{Comparison: Reference vs. Alternative Concept}

The exemplarily shown simulation results serves as basis for calculating the systemic storage densities, heat losses and thermal cooling powers as well as for evaluation of the alternative concept in comparison to the reference. For this purpose, Figure 8 illustrates the systemic storage densities resulting from the wide simulation studies as a function of the thermal cooling power.

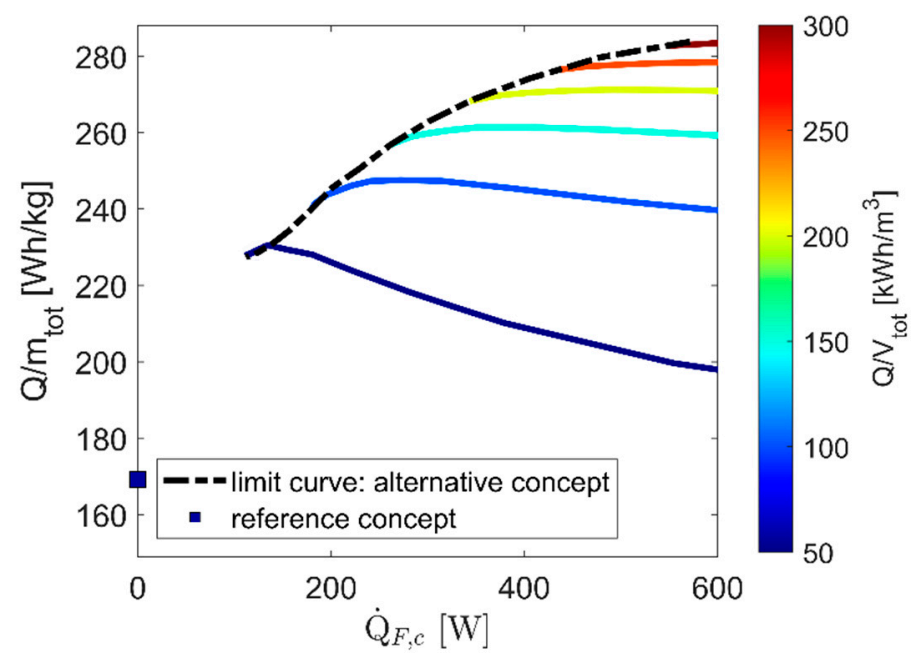

Figure 8. Systemic storage densities of the reference and the alternative concept as a function of the resulting thermal cooling powers $\left(\dot{Q}_{F, c}\right)$.

The reference concept without active cooling $\left(\dot{Q}_{F, c}=0\right)$ reaches a volumetric and gravimetric systemic storage density of $169.2 \mathrm{Wh} / \mathrm{kg}$ and $56.3 \mathrm{kWh} / \mathrm{m}^{3}$ at the maximum permitted surface temperature of $60^{\circ} \mathrm{C}$, whereas the alternative concept achieves storage densities of up to $284.9 \mathrm{Wh} / \mathrm{kg}$ and $311.3 \mathrm{kWh} / \mathrm{m}^{3}$. These improvements are based on the integrated bypass and the associated active thermal cooling powers $\left(\dot{Q}_{F, c}\right)$. At the limit case-minimal active cooling powers depending on the gravimetric systemic storage densities (black curve)-thermal cooling powers from $123.4 \mathrm{~W}$ to $600 \mathrm{~W}$ are needed within the scope of the investigated gap and thermal insulation thicknesses. Due to additional considered storage medium dimensions within the systemic storage densities, the minima in the thermal insulation masses as shown in Figure 7 are only weakly visible here.

In addition to the systemic storage densities and thermal cooling powers, the resulting heat losses serve as a further value for comparison and evaluation of the alternative concept (Figure 9). 


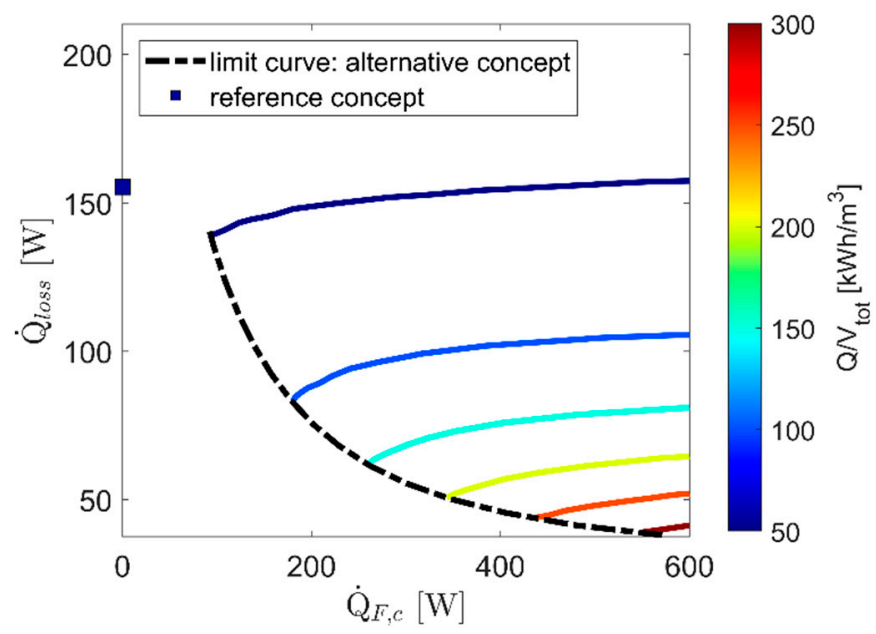

Figure 9. Heat losses $\left(\dot{Q}_{\text {loss }}\right)$ and volumetric systemic storage densities of the reference and the alternative concept as a function of the resulting thermal cooling powers $\left(\dot{Q}_{F, c}\right)$

As already described in Section 4.2.2, the results show that increased cooling powers $\left(\dot{Q}_{F, c}\right)$ are associated with reductions in storage dimensions and thus in heat losses $\left(\dot{Q}_{\text {loss }}\right)$. In relation to the limit case-minimal active cooling powers depending on the gravimetric systemic storage densities (black curve). This results in a decrease in heat loss from $155.3 \mathrm{~W}$ for the reference concept to up to $38 \mathrm{~W}$ for the alternative concept.

The presented results point to significant improvements in systemic storage densities with minor thermal cooling powers through the integration of the bypass path inside the thermal insulation. For the limit cases-illustrated by the black curves- the associated insulation and gap thicknesses are shown in Figure 10.

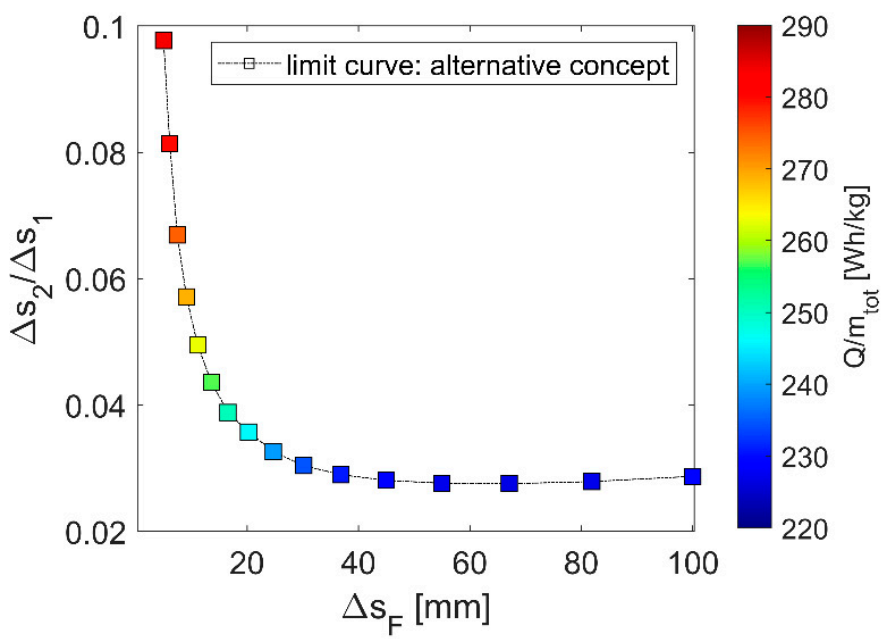

Figure 10. Ratio of outer to inner thermal insulation thickness $\left(\Delta s_{2} / \Delta s_{1}\right)$ and gravimetric systemic storage densities $\left(Q / m_{t o t}\right)$ for the limit case as a function of the cooling fluid gap $\left(\Delta s_{F}\right)$.

The context between decreasing gap thicknesses $\left(\Delta s_{F}\right)$ and increasing systemic storage densities (coloured dots) due to the associated improved cooling efficiency becomes visible, as already described previously. In addition, the results show that the inner insulation $\left(\Delta s_{1}\right)$ dominates and makes the essential contribution to total thermal insulation. This effect is caused by significantly decreasing heat transports via radiation with increasing inner insulation thickness and leads-together with the convective cooling - to small required outer thermal insulation dimensions. Even by very small fluid gaps and thus high convective cooling rates, the inner thermal insulation thickness dominates with over $90 \%$ compared to the outer one. 
Based on these first results and contexts presented here, the systemic advantages of the alternative concept become obvious. Compared to the specified thermal discharge power of $5000 \mathrm{~W}$, only low active cooling rates of less than $600 \mathrm{~W}$ are required even at design solutions with high systemic storage densities of up to $284.9 \mathrm{Wh} / \mathrm{kg}$ and $311.3 \mathrm{kWh} / \mathrm{m}^{3}$.

For a selected example system with a total thermal output of $500 \mathrm{~W}$ from active cooling and heat loss at the end of the charging period, the central results for the alternative concept are summarized in Table 7.

Table 7. Example system of the alternative concept—central results at maximum permitted surface temperature and maximum cooling flow outlet temperatures of each $60^{\circ} \mathrm{C}$.

\begin{tabular}{cccccccc}
\hline$Q / m_{\text {tot }}[\mathrm{Wh} / \mathrm{kg}]$ & $Q / V_{\text {tot }}\left[\mathrm{kWh} / \mathrm{m}^{3}\right]$ & $\dot{Q}_{\text {loss }}[\mathrm{W}]$ & $\dot{Q}_{F, c}[\mathrm{~W}]$ & $\dot{m}_{F, c}[\mathrm{~kg} / \mathrm{h}]$ & $\Delta s_{1}[\mathrm{~mm}]$ & $\Delta s_{2}[\mathrm{~mm}]$ & $\Delta s_{F}[\mathrm{~mm}]$ \\
\hline 278.1 & 261.4 & 42.6 & 457.4 & 25.1 & 26.1 & 2 & 6.5 \\
\hline
\end{tabular}

This selected design solution with maximum pressure losses in the gap [39] of less than 1 mbar shows increases in volumetric and gravimetric storage densities compared to the reference concept (Table 6) by the factor 4.65 and 1.65 as well as a decrease in heat losses by the factor 3.65. Furthermore, the required low thermal cooling power of $457.4 \mathrm{~W}(<10 \%$ of the thermal discharge power) can be used as operational strategy for thermal preheating of the vehicle cabin and thus enables an efficient use of the cooling outlet temperature of $60^{\circ} \mathrm{C}$ at the end of the charging period.

\section{Conclusions}

The use of thermal energy storage systems opens up new paths for the heat supply in battery-electric vehicles and increases the range by reducing battery-electric capacity. Efficient concepts of such thermal storage systems are based on electrically heated high-temperature solid media that enable efficient and cost-effective solutions through a wide range of ceramic or metallic storage medium materials and powerful electrical heating elements. However, for previously investigated thermal storage concepts, the required thermal insulation dimensions limit the systemic storage densities due to safety restrictions in the maximum permitted surface temperature. To overcome such limitations, an alternative thermal insulation concept was presented and systematically investigated.

The alternative thermal insulation concept is based on the integration of the external bypass-to ensure a constant temperature during discharge operation-inside the thermal insulation. As a result, previously unused heat inside the thermal insulation as well as heat losses can be integrated in the bypass path during the discharging period and a reduction of insulation thickness can be achieved through active cooling during charging period. The results, which have so far only focused on the charging process, confirm an increase of systemic storage densities from $169.2 \mathrm{Wh} / \mathrm{kg}$ and $56.3 \mathrm{kWh} / \mathrm{m}^{3}$ for the reference concept to up to $284.9 \mathrm{Wh} / \mathrm{kg}$ and $311.3 \mathrm{kWh} / \mathrm{m}^{3}$ for the alternative concept. At the same time, the existing heat losses are reduced from $155.3 \mathrm{~W}$ to up to $38 \mathrm{~W}$, in which the low required thermal cooling output powers of $123.4 \mathrm{~W}$ to $600 \mathrm{~W}$ at a temperature of $60^{\circ} \mathrm{C}$ can be used directly for preheating concepts. Comparing the thermal storage densities of the alternative concept with those of battery powered heating systems operating in a range from $100 \mathrm{Wh} / \mathrm{kg}$ to $180 \mathrm{Wh} / \mathrm{kg}$ [18] for today's commercial Li-Ion systems, the vehicle-systemic benefits are obvious and the drawbacks in terms of lower exergetic potentials can be overcome.

Actual studies focus on the advantage of the alternative concept during thermal discharging period and a holistic based optimization regarding both process steps. Additional improvements in the systemic storage densities associated with this, along with constructive designs for the integrated bypass path and with first design calculations for the high-temperature electric heating system, are central focuses of further works. A promising and holistic based solution of such a thermal energy storage system form the basis for designing a prototype and experimental investigations. 
Funding: This research received no external funding.

Conflicts of Interest: The author declares no conflict of interest.

\section{Nomenclature}

\begin{tabular}{|c|c|}
\hline D & Inventory diameter $[\mathrm{m}]$ \\
\hline $\mathbf{L}$ & Inventory length [m] \\
\hline$\Delta s$ & Insulation thickness $[\mathrm{m}]$ \\
\hline $\mathbf{V}$ & Volume $\left[\mathrm{m}^{3}\right]$ \\
\hline m & Mass [kg] \\
\hline av & Specific surface $\left[\mathrm{m}^{2} / \mathrm{m}^{3}\right]$ \\
\hline$\varepsilon$ & Void fraction \\
\hline $\mathbf{w}$ & Velocity $[\mathrm{m} / \mathrm{s}]$ \\
\hline$\alpha$ & Heat transport coefficient $\left[\mathrm{W} / \mathrm{m}^{2} \mathrm{~K}\right]$ \\
\hline k & Total heat transfer coefficient $\left[\mathrm{W} / \mathrm{m}^{2} \mathrm{~K}\right]$ \\
\hline $\mathbf{t}$ & Time [s] \\
\hline $\mathrm{z}$ & Axial dimension $[\mathrm{m}]$ \\
\hline $\mathbf{r}$ & Radial dimension $[\mathrm{m}]$ \\
\hline$\rho$ & Density $\left[\mathrm{kg} / \mathrm{m}^{3}\right]$ \\
\hline $\mathbf{c}_{\mathbf{P}}$ & Specific heat capacity $[\mathrm{J} / \mathrm{kgK}]$ \\
\hline$\lambda$ & Heat conduction $[\mathrm{W} / \mathrm{mK}]$ \\
\hline $\mathbf{a}$ & Thermal diffusivity $\left[\mathrm{m}^{2} / \mathrm{s}\right]$ \\
\hline $\mathbf{T}$ & Temperature [K] \\
\hline Q & Thermal energy [J] \\
\hline$\dot{Q}$ & Thermal power [W] \\
\hline$\dot{m}$ & Mass flow rate $[\mathrm{kg} / \mathrm{s}]$ \\
\hline$\tau$ & Duration [s] \\
\hline$\eta_{\text {store }}$ & Thermal utilization coefficient \\
\hline $\mathrm{p}$ & Pressure loss [Pa] \\
\hline $\mathrm{C}_{\mathrm{r}}$ & Radiation parameter $\left[\mathrm{W} / \mathrm{m}^{2} \mathrm{~K}^{4}\right]$ \\
\hline \multicolumn{2}{|c|}{ Subscripts } \\
\hline S & Solid \\
\hline $\mathbf{F}$ & Fluid \\
\hline Ins & Thermal insulation \\
\hline j & Inner $(j=1)$ and outer $(j=2)$ thermal insulation \\
\hline $\mathbf{U}$ & Environment \\
\hline $\mathbf{W}$ & Surface area \\
\hline c & Active cooling fluid \\
\hline $\operatorname{mix}$ & Mixing temperature \\
\hline PtH & Maximum solid media storage temperature \\
\hline loss & Heat losses \\
\hline tot & Solid medium and thermal insulation \\
\hline SM & Solid medium \\
\hline
\end{tabular}

\section{References}

1. Grossmann, H. Pkw-Klimatisierung-Physikalische Grundlagen und Technische Umsetzung; Springer: Berlin/Heidelberg, Germany, 2013.

2. Kuper, C.; Hoh, M.; Houchin, G.-M.; Fuhr, J. Thermal Management of Hybrid Vehicle Battery Systems; EVS24: Stavanger, Norway, 2009.

3. Jung, M.; Kemle, A.; Strauss, T.; Wawzyniak, M. Innenraumheizung von Hybrid-Und Elektrofahrzeugen; ATZ: Vancouver, BC, Canada, 2011; pp. 396-401.

4. Knote, T. Ansätze Zur Standardisierung Und Zielkosten Für Elektrobusse; Fraunhofer IVI: Dresden, Germany, 2017.

5. Pischinger, S.; Genender, P.; Klopstein, S.; Hemkemeyer, D. Aufgaben Beim Thermomanagement Von Hybrid—Und Elektrofahrzeugen; ATZ: Vancouver, BC, Canada, 2014; pp. 54-59. 
6. Heiligenstaedt, W. Wärmetechnische Rechnungen für Industrieöfen. In 4. Aufl; Stahleisen: Düsseldorf, Germany, 1966.

7. Amelio, M.; Morrone, P. Numerical evaluation of the energetic performances of structured and random packed beds in regenerative thermal oxidizers. Appl. Therm. Eng. 2007, 27, 762-770. [CrossRef]

8. Dreißigacker, V.; Belik, S. System configurations and operational concepts for high efficient utilization of Power-to-Heat in A-CAES. Appl. Sci 2019, 9, 1317. [CrossRef]

9. Benato, A.; Stoppato, A. Pumped Thermal Electricity Storage: A technology overview. Therm. Sci. Eng. Prog. 2018, 6, 301-3015. [CrossRef]

10. Turner, R.H. High Temperature Thermal Energy Storage; Franklin: Philadelphia, PA, USA, 1978.

11. Fricker, H.W. Regenerative Thermal Storage in Atmospheric Air System Solar Power Plants. Energy 2004, 29, 871-881. [CrossRef]

12. Pacheco, J.E.; Showalter, S.K.; Kolb, G.J. Development of a Molten-Salt Thermocline Thermal Storage System for Parabolic Trough Plants. J. Sol. Energy Eng. 2002, 124, 153-159. [CrossRef]

13. Tamme, R.; Laing, D.; Steinmann, W.D. Advanced Thermal Storage Technology for Parabolic Trough. J. Sol. Energy Eng. 2004, 126, 794-800. [CrossRef]

14. Steinmann, W.D.; Tamme, R. Latent Heat Storage for Solar Steam Systems. In Proceedings of the 13th Solar-PACES Int. Symposium on Concentrated Solar Power and Chemical Energy Technology, Sevilla, Spain, 20-23 June 2006.

15. De Maria, G.; D'Alessio, L.; Coffaria, E.; Paoluccia, M.; Tiberio, C.A. Thermochemical storage of solar energy with high-temperature chemical reactions. Solar Energy 1938, 35, 409-416. [CrossRef]

16. Linder, M.; Utz, I.; Schaube, F.; Molenda, M.; Wörner, A. Gas-Solid Reactions for Heat Applications. In Proceedings of the 5th Hydrogen \& Energy Symposium, Stoos, Schweiz, 23-28 January 2011.

17. Ugurlu, A.; Gokcol, C. A review on thermal energy storage systems with phase change materials in vehicles. Electron. J. Vocat. Coll. 2012, 2, 1-14.

18. Kraft, W.; Stahl, V.; Vetter, P. Thermal Storage Using Metallic Phase Change Materials for Bus-State of the Art of Electric Buses and Requirements for the Storage System. Energies 2020, 13, 3023. [CrossRef]

19. Kraft, W.; Jilg, V.; Altstedde, M.K.; Lanz, T.; Vetter, P.; Schwarz, D. Thermal High Performance Storages for Use in Vehicle Applications. In Proceedings of the 2nd ETA Conference, Berlin, Germany, 2-23 November 2018.

20. Korin, E.; Reshef, R.; Tshernichovesky, D.; Sher, E. Improving Cold-Start Functioning of Catalytic Converters by Using Phase-Change Materials. SAE Tech. Pap. Ser. 1998. [CrossRef]

21. Gumus, M. Reducing cold-start emission from internal combustion engines by means of thermal energy storage system. Appl. Therm. Eng. 2009, 29, 652-660. [CrossRef]

22. Kato, Y. Thermal energy storage in vehicles for fuel efficiency improvement. Proc. Effstock 2009. Available online: http:/intraweb.stockton.edu/eyos/energy_studies/content/docs/effstock09/Session_3_1_Efficient_Soultions_using short_term_TES/2.pdf (accessed on 12 November 2020).

23. Dieterich, M.; Bürger, I.; Linder, M. Open and closed metal hydride system for high thermal power applications: Preheating vehicle components. Int. J. Hydrog. Energy 2017, 11469-11481. [CrossRef]

24. Dreißigacker, V.; Belik, S. High temperature solid media thermal energy storage system with high effective storage densities for flexible heat supply in electric vehicles. Appl. Therm. Eng. 2018. [CrossRef]

25. Sergej, B.; Dreißigacker, V.; Dieterich, M.; Kraft, W. Next Generation Car Thermal energy storage systems: Power-to-Heat concept in solid media storage for high storage densities. In Proceedings of the EVS30 Symposium, Stuttgart, Germany, 9-11 October 2017.

26. Kanthal. Iron-Chromium-Aluminium (Fecral) Wire Alloys. Available online: https://www.kanthal.com/en/products/ materials-in-wire-and-strip-form/wire/list-of-alloys/list-of-fecral-alloys (accessed on 12 November 2020).

27. Thackeray, M.M.; Wolverton, C.; Isaacs, E.D. Electrical energy storage for transportation-Approaching the limits of, and going beyond, lithium-ion batteries. Energy Environ. Sci. 2012, 5, 7854-7863. [CrossRef]

28. Ismail, K.A.R.; Stuginsky, R. A parametric study on possible fixed bed models for pcm and sensible heat storage. Appl. Therm. Eng. 1999, 19, 757-788. [CrossRef]

29. Hausen, H. Wärmeübertragung im Gegenstrom, Gleichstrom und Kreuzstrom; Springer: Verlag, France, 1976.

30. Schmidt, F.W.; Willmott, A.J. Thermal Energy Storage and Regeneration; McGraw-Hill Book Company: New York, NY, USA, 1981.

31. Lemmon, E.W.; Jacobsen, R.T.; Penoncello, S.G.; Friend, D.G. Thermodynamic properties of air and mixtures of nitrogen, argon and oxygen from 60 to $2000 \mathrm{~K}$ at Pressures to $2000 \mathrm{MPa}$. J. Phys. Chem. Ref. Data 2000, 29, 331-385. [CrossRef] 
32. Carslaw, H.S.; Jaeger, J.C. Conduction of Heat in Solids; Clarendon Press: Oxford, UK, 1967.

33. Gnielinski, V. Wärmeübertragung Im Konzentrischen Ringspalt Und Im Ebenen Spalt; VDI-Wärmeatlas; Springer Berlin Heidelberg: Wiesbaden, Germany, 2013.

34. Churchill, S.W.; Chu, H.H.S. Correlating equations for laminar and turbulent free convection from a vertical plate. Int. J. Heat Mass Transf. 1975, 18, 1323-1329. [CrossRef]

35. Howell, J.; Siegel, R.; Mengüç, M.P. Thermal Radiation Heat Transfer; CRC press: Cleveland, OH, USA, 2010.

36. Archer, D.G. Thermodynamic Properties of Synthetic Sapphire ( $\alpha$-Al2O3), Standard Reference Material 720 and the Effect of Temperature-Scale Differences on Thermodynamic Properties. J. Phys. Chem. Ref. Data 1993, 22, 1441. [CrossRef]

37. Silca. SILCAFLEX Ceramic Fibre Products. Available online: https://www.silca-online.de/en/thermalinsulation/ceramic-fibre-products/silcaflex.html (accessed on 12 November 2020).

38. DIN EN ISO 13732-1:2008-12. Ergonomie der thermischen Umgebung-Bewertungsverfahren für menschliche Reaktionen bei Kontakt mit Oberflächen- Teil 1: Heiße Oberflächen. Available online: https://www.din. de/de/mitwirken/normenausschuesse/naerg/veroeffentlichungen/wdc-beuth:din21:111624965 (accessed on 12 November 2020).

39. VDI Gesellschaft. VDI-Wärmeatlas; Springer: Berlin/Heidelberg, Germany; Wiesbaden, Germany, 2005.

Publisher's Note: MDPI stays neutral with regard to jurisdictional claims in published maps and institutional affiliations.

(C) 2020 by the author. Licensee MDPI, Basel, Switzerland. This article is an open access article distributed under the terms and conditions of the Creative Commons Attribution (CC BY) license (http://creativecommons.org/licenses/by/4.0/). 